\title{
Nutritional Status of Preschoolers in Four Selected Fisher Communities
}

\author{
Md. Abdul Hakim, ${ }^{1, ~ *, ~ M d . ~ K a m r u z z a m a n ~}{ }^{2}$ \\ ${ }^{1}$ Department of Food Technology and Nutritional Science, Faculty of Life Science, Mawlana Bhashani Science and Technology University, \\ Santosh, Tangail, Bangladesh \\ ${ }^{2}$ Department of Criminology and Police Science, Faculty of Life Science, Mawlana Bhashani Science and Technology University, Santosh, \\ Tangail, Bangladesh
}

Email address:

info.hakim.bd@gmail.com (M. A. Hakim), shohag.mbstu.cps@gmail.com (M. Kamruzzaman)

\section{To cite this article:}

Md. Abdul Hakim, Md. Kamruzzaman. Nutritional Status of Preschoolers in Four Selected Fisher Communities. American Journal of Life Sciences. Vol. 3, No. 4, 2015, pp. 332-336. doi: 10.11648/j.ajls.20150304.22

\begin{abstract}
The current study was conducted in the four selected fisher communities in Bangladesh. The communities were at random to take part the Satkhira, Patuakhali, Mymensingh and Tangail districts fisher communities. There were sorted $46 \%$ $(n=54)$ girls and $55 \%(n=66)$ boys from the communities by using simple random sampling method to carry on the study. Results divulged to contribute $30 \%(n=36)$ underweight, $22.5 \%(n=27)$ stunted and $12.5 \%(n=15)$ wasted preschoolers in the four selected fisher communities. The smoking and alcoholism prevalence of the fathers of preschoolers were found $72.5 \%(\mathrm{n}=87)$ and $10 \%(\mathrm{n}=12)$. The apt method of disposal of child excreta and safe water using in cooking and drinking purposes were $80.8 \%$ $(n=97)$ and $90.8 \%(n=109)$ respectively. The study also showed that $69.2 \%(n=83)$ fathers and $66.7 \%(n=80)$ mothers of the preschoolers attained education up to the PSC level. Parental education level, father's alcoholism and smoking patterns, method adopted to dispose child excreta and frequent use of safe water for drinking and cooking assay were closely linked to attain the attained nutritional status of the preschoolers in the target population.
\end{abstract}

Keywords: Nutritional Status, Preschoolers, Fisher Communities

\section{Background}

The "fisher communities" defined as the self-employed group of peoples on the occupation of fish or other water body animals' capturers [1]. There were about 38 million commercial and subsistence fisher worldwide in 2002, more than triple the number in 1970. Of this total, $26 \%$ were aquaculturists and $74 \%$ worked in fisheries capturing. The total fishery produce of 133 million tones equated to an average 3.5 tonnes productivity per capita according to the FAO and most of this growth in Asian countries, where four-fifth of world's fishers dwell. Most fisher is involved in offshore and deep sea fisheries to sprint their professionalism. Fisherwomen are the nets makers or repairers, post-harvest processing and marketing performers and they often catch fishes in inshore from little boats or collect shellfishes and seaweeds [2]. The "fishing" term is also applicable to recreational fisher as a means of obtaining food since the Mesolithic period [3]. Fisher provides the premier proportion of food for the Egyptians during the Ancient Egyptians as a means of prime survival venture [4]. Fishing does not only imply to get a food source but also the cultural identity to the occupational fisher in the world [5]. Fishing is a hazardous work and the fatality rate is on the rise day by day on account of lack of technical supports and rules denying gesture. The one-third of work-related deaths receivers were fisher out of 948 in Alaska during 1990 to 2006 receiving the fatality rate of 128/100,000 workers/year [6]. Fisher is the bread and cheese earners by the sweet of their brow in offshore and the sea with a view to easy attitude to earn their livelihoods. Their children are the minor, not born under a lucky star, not once in a way with malnutrition and hidden hunger $[7,8]$ leading their reduced nutritional status, the big headache of the fisher communities as they're the cat's paw to their poverty by dint of scarce economic boosters and their infants and preschoolers are the class 1 vulnerable on the track to adopt these multidimensional perils at their 3R's life cycle to meet severe public health perils [9]. The abundance of dietary malpractices in course of daily main meals and snacks taking schedule in developing countries lead astray the nutritional soundness of the population a laughing stock. The reluctance of dieting 
maintenance regularly due to their families, social, cultural, demographic and heredity studies are the malnutrition causal catalysts $[10,11]$. Childhood malnutrition remains one of the most challenging global public health panics. Malnutrition magnitude revealing and underlying socio-cultural factors influencing feeding and raring is essential to combat these existing perils in the societies. Persistence of malnutrition undetected and without any appropriate interventions shown to be having profound and frightening implications for children, society and the future of the entire mankind. A meta analysis revealed that children of 0.5 to 5 years of age of age with mild to moderate malnutrition had 2.2 times higher risk of mortality and 6.8 times higher risk for severely malnourished during the follow up period than their better nourishment counter [12]. A considerable proportion of underweight (21.1\%), stunting (17.3\%) and wasting (14.7\%) prevailing among preschoolers in Sri Lanka according to the survey conducted by the department of census and statistics [13].

The physical, social and mental growth and development of children's life takes place rapidly in the first few staring years. If this increased demand isn't met, considerable retardation in growth can occur during the early childhood leading to adverse impact such as mortality, morbidity, reduce intellectual performances and late outcome in reducing working efficiency and productivity [14].

Being the island surrounded by the sea, marine fisheries industry is considered to be an important industry in Sri Lanka accounts to about 441,707 populations of total fishing households [15]. The Bangladeshi fisher is to lead a low life style and behavioral attitude due to inadequate economic gaining while the Sri Lankan fisher the satisfactory earner and according to the Leitan majority of them are smokers and alcoholics [16].

Therefore the current study was conducted to assess the nutritional status and to probe into different selected factors affecting the preschoolers in the four selected fisher communities in Bangladesh.

\section{Methodology}

\subsection{Study Type}

The study was a cross-sectional study.

\subsection{Study Areas}

The four selected Satkhira, Patuakhali, Mymensingh and Tangail districts fisher communities were the areas to conduct the study.

\subsection{Population Sampling}

There were taken a total of 120 preschoolers from Kalaroa upazila of Satkhira (30 preschoolers), Bauphal upazila of Patuakhali (30 preschoolers), Baluka upazila of Mymensingh (30 preschoolers) and Porabari, Charabari, Santosh villages from Tangail Sadar upazila of Tangail (30 preschoolers) district fisher communities in Bangladesh.

\subsection{Sampling Method}

The simple random sampling method was adorned to sort the children in four selected topography.

\subsection{Age Consideration}

1 to 5 years-old children were in use for the study according the UNESCO's preschool age detection standard.

\subsection{Data Collection Method}

A questionnaire was prepared containing the closed and open ended query in order to collect all the essential assessment.

\subsection{Anthropometric Data}

The anthropometric data were measured applying the following tricks:

\subsubsection{Weight Measurement}

The weight of the study participants were measured using standardized salter and seca weighing scales.

\subsubsection{Height Measurement}

The height of the study participants were measured using height measuring tape and standard height board.

\subsection{Nutritional Status Assessment}

The Z-score were calculated for height-for-age, weight-for-height and weight-for-age. The underweight, stunted and wasted prevalence were determined using Z-score $<$ -2 SD of height-for-age, weight-for-height and weight-for-age relatively of the CDC/NCHS (2000) reference standards and other standard variables were found applying the preplanned designed questionnaire.

\subsection{Data Verification}

Questionnaires were checked each day after interviewing and again carefully checked completing all the data collection and coded before entering into the computer technology. The data was edited if there sighted any discrepancy (doubt entry, wrong entry etc.).

\subsection{Data Analysis}

The collected data was analyzed through the widespread application of SPSS 16 windows program. Microsoft Word and Microsoft Excel were used in this connection.

\section{Results}

Table 1. Age and sex induced grouping of children.

\begin{tabular}{llll}
\hline & & Frequency & Percentage \\
\hline \multirow{4}{*}{ Age (years) } & 1 to 2 & 24 & 20 \\
& 2 to 3 & 24 & 20 \\
& 3 to 4 & 24 & 20 \\
Sex & 4 to 5 & 24 & 20 \\
& Girls & 54 & 45 \\
& Boys & 66 & 55 \\
\hline
\end{tabular}


Table 1 is the detector of $46 \%(n=54)$ girls and $55 \%(n=66)$ boys comprising a total of 120 preschoolers in the selected Satkhira, Patuakhali, Mymensingh and Tangail districts fisher communities in Bangladesh and there were $20 \%(n=24) 1$ to 2 , 2 to 3,3 to 4 and 4 to 5 years children in the respective communities.

Table 2. Weight-for-age grouping of children.

\begin{tabular}{lll}
\hline Weight-for-age & Frequency & Percentage \\
\hline Underweight & 36 & 30 \\
Normal weight-for-age & 84 & 70 \\
Total & 120 & 100 \\
\hline
\end{tabular}

Table 3. Height-for-age grouping of children.

\begin{tabular}{lll}
\hline Height-for-age & Frequency & Percentage \\
\hline Stunted & 27 & 22.5 \\
Normal height-for-age & 93 & 77.5 \\
Total & 120 & 100 \\
\hline
\end{tabular}

Table 4. Weight-for-height grouping of children.

\begin{tabular}{lll}
\hline Weight-for-height & Frequency & Percentage \\
\hline Wasted & 15 & 12.5 \\
Normal weight-for-height & 105 & 87.5 \\
Total & 120 & 100 \\
\hline
\end{tabular}

The table 2, 3 and 4 represented the prevalence of different forms of malnutrition on the particular population in the selected communities were $30 \%(\mathrm{n}=36)$ underweight, $22.5 \%$ $(\mathrm{n}=27)$ stunted and $12.5 \%(\mathrm{n}=15)$ wasted beyond $70 \%(\mathrm{n}=84)$ normal weight-for-age, $77.5 \%(\mathrm{n}=93)$ normal height-for-age and $87.5 \%(n=105)$ normal weight-for-height on the basis of the respective Z-score in different tables by turns in the study.

Table 5. Grouping of study population based on the parental socio-demographic contour.

\begin{tabular}{llll}
\hline Variables & Category & Frequency & Percentage \\
\hline Level of & No schooling & 25 & 20.8 \\
education of & Up to the PSC & 80 & 66.7 \\
mother & Up to the SSC and above & 15 & 12.5 \\
Level of & No schooling & 10 & 8.3 \\
education of & Up to the PSC & 83 & 69.2 \\
father & Up to the SSC and above & 27 & 22.5 \\
Ability of the & Able & 93 & 77.5 \\
mother to read & Unable & 27 & 22.5 \\
Ability of the & Able & 99 & 82.5 \\
father to read & Unable & 21 & 17.5 \\
Father's & Smoking & 87 & 72.5 \\
substance to & Alcohol & 12 & 10 \\
abuse & Apt & 97 & 80.8 \\
$\begin{array}{l}\text { Method of } \\
\text { disposal of }\end{array}$ & Wrong & 23 & 19.2 \\
child excreta & Yes & 109 & 90.8 \\
$\begin{array}{l}\text { Using safe } \\
\text { water in }\end{array}$ & & 11 & 9.2 \\
$\begin{array}{l}\text { cooking and } \\
\text { drinking }\end{array}$ & No & & \\
\hline
\end{tabular}

Table 5 represented to contribute $12.5 \%(n=15)$ and $66.7 \%$ $(\mathrm{n}=80)$ education level up to the SSC and above and up to the PSC of the children's mother while $22.5 \%(n=27)$ and $69.2 \%$ $(n=83)$ education earners up to the SSC and above and up to the PSC for the children's father respectively. There were $17.5 \%$ $(n=21)$ father unable to read and $77.5 \%(n=93)$ mother able to read and there were $90.8 \%(n=109)$ safe water users for drinking and cooking purposes and 19.2\% $(n=23)$ wrong method users to dispose child excreta at their households. The mother's literacy level had association to wasting and underweight, father's smoking and alcoholism states significantly related with stunting, wasting and underweight of their children and method of disposal of excreta found to be significantly associated with underweight and safe water using was related to perform hygienic life standard.

\section{Discussion}

There are huge fisher communities at different topography in Bangladesh as Bangladesh is a land of rivers [17]. The children of the fisher in Bangladesh are in deprivation to their rights to survival, nutrition, health, education and safe water. The study covered the important fisher communities to represent the fisher as a whole in Bangladesh. Most of the fisher is the PSC level education achievers and their educational standard is higher in fisher than fisherwomen according to the study. There is abundance of up to the PSC and some are up to the SSC level education earner and very few aren't in school entry at all. The ray of light of education hardly reaches to their retina $[18,19]$ in full swing to continue a very miserable social, cultural, economic and occupational life. They are at bay to maintain the balanced diet planning heading the malnutrition in various dimensions [20]. They are too poor to take their care for their health as $46 \%$ fisher received health service from quack, $18 \%$ have access to upazila health complex and 14\% went to district hospital, 20\% consulted with the MBBS doctors and 2\% are deprived of taking treatment by dint of prevailing pauperism [21, 22].

There are vast malnutrition intensity in Bangladesh to make Bangladesh a trademark of malnutrition prone landscape in the world as there are $30 \%$ underweight prevalence in Southern Asia, more than $90 \%$ of world's stunned children in Asia and Africa and about $70 \%$ of the world's wasted children in Asia, most in South-Central Asia [23].

These perilous affairs are likely to expose $30 \%$ underweight, $22.5 \%$ stunted and $12.5 \%$ wasted preschool children in the four selected fisher communities in Bangladesh according to the concerned study as like as different studies conducted in different time frame in different countries [24, 25].

According to the present study, a significant association was found between the mothers' and fathers' ability to read, father being an alcoholic and a smoker and practice of wrong method to dispose child excreta. A study done on children attaining the age of 2 years, living in the University community health project area, Kotte in Sri Lanka mother's level of education was found to be influencing the nutritional status of children [26-28].

Another study done in a diarrheal unit in large metropolitan city socio demographic indicators such as unhygienic latrine, unprotected surface water and maternal literacy have found to 
be significantly associated with severe malnutrition in their children [29]. Father's and mother's education, wealth index, source of drinking water of the household, toilet facility and total number of children ever born with child malnutrition in Bangladesh [30].

Father's substance abuse is indicates the negative impact on the nutritional status of the children according to the present findings. Father being an alcoholic and a smoker leading to financial instability may be the probable explanation for the above association elicited in the current study. According to a survey in Bangladesh, it has shown that smoking five cigarettes a day in a household could lead to a monthly dietary deficit of 8000 calories, nearly a quarter of the monthly maintenance of energy requirement of a 12 kilograms weighing child [31] and further explains is also associated. Considering the overall study, it felt that the preschooler's mother in the study is to be more educated than the ongoing conditions to support their children's better dietary, sanitation facilities and hygiene practices to make sure their preschooler's safe childhood [27, 32].

\section{Conclusion}

The present study findings revealed that the malnutrition problem is multifaceted and has different association with socio-economic and demographic factors. The preschoolers are the galore vulnerable in their existing societies being affected and later experienced by various unhygienic conditions in the fisher communities in Bangladesh. Educational programs and health, nutrition and water, sanitation and hygiene campaigning should organize in different occasions in different communities and continuation of follow up of these programs fairly in order is essential to enlighten the preschoolers of fisher communities and forming healthy population shirking the bulk of the concerned malnourishment for the ultimate interest of the country.

\section{Abbreviations}

PSC: Primary School Certificate; SSC: Secondary School Certificate; MBBS: Bachelor of Medicine, Bachelor of Surgery.

\section{References}

[1] 45-3011 Fishers and Related Fishing Workers. US Department of Labor.

[2] FAO: Fishing people. Retrieved July 7, 2008.

[3] Early humans followed the coast. BBC News article.

[4] Fisheries history.

[5] International Collective in Support of Fishworks (ICSF).

[6] NIOS Commercial Fishing in Alaska. United States National Institute of Occupational Safety and Health. Retrieved October $13,2007$.
[7] Muller O, Krawinkel M (2005). Malnutrition and health in developing countries. CMAJ 173 (3): 279-286.

[8] Tontisrin K, Nantel G, Bhattacharjee L (2002). Food-based strategies to meet the challenges of micronutrient malnutrition in the developing world. Proceeding of the Nutrition Society. $61(2(: 243-250$.

[9] De Onis, M. and Hubicht, JP. (1997). Anthropometric reference data for international use: recommendation from a WHO expert committee, food and nutrition bulletin, 18 (2): 179-188.

[10] Curtis VA, Danquah LO, Aunger R (2009). Planned, motivated and habitual hygiene behaviour: an eleven country review. Health Educ Res 24 (4): 655-673.

[11] M. S. Aktar, N. Bhatty, M. Sattar and M. T. Javed (2001). Comperison of Nutritional Status in Children of Different socio-economic Statuses. Medical Journal of Islamic Academy of Sciences. Vol 14, no. 3; pp. 97-102.

[12] Schroeder, D. J., Brown, K. H. Nutritional status as a predictor of child survival: summarizing the association and quantifying its global impact, Bull World Health Organ (1994). 72 (4): 569-579.

[13] Demographic and health survey -2006/07, Department of Census and Statistics, Colombo, Sri Lanka, chapter-11. Nutrition of children and women, pp 135-158.

[14] Garros, J. S., Human nutrition dietetics, Chapter 2; 1987, pp 13-15.

[15] Department of Census and Statistics, statistical abstract 2001, Chapter 7.

[16] Leitan, T. (1995). Women in fishing industry, Centre for society and religion.

[17] River and Drainage system. Bangladesh: national Encyclopedia of Bangladesh. Banglapedia 2012, Retrieved October 12, 2014.

[18] Sensory Reception: Human vision: Structure and function of the Human Eye. Vol 27, Encyclopedia Britannica, 1987.

[19] Shepherd, Gordon (2004). The Synaptic Organization of the Brain. New York, NY: Oxford University Press. pp. 217-225. ISBN 978-0-19-515956-1.

[20] Sen, A. 1989. Food and Freedom. World Development 17 (6): 769-781.

[21] M. H. Ali, M. D. Hossain and M. A. Bashar. Assessment of livelihood status of the fish farmers in some selected areas of Bagmara upazila under Rajshahi district. J. Bangladesh Agril. Univ. 6 (2): 367-374.

[22] Thorpe, A., Reid, R. van Anrooy and C. Brugere (2004). African Poverty reduction Strategy Programmes and the fisheries Sector. Current Situation and Opportunities. African development Review 16 (2): 328-362.

[23] United Nations Children's Fund, World Health Organization, The World Bank. UNICEFWHO-World Bank Joint Child Malnutrition Estimates. (UNICEF, New York; WHO, Geneva; The World Bank, Washington, DC; 2012.

[24] Peiris, T.D.R. and D.G.N.G. Wijesinghe, Nutritional status of under 5 Year-Old Children and its Relationship with Maternal Nutrition Knowledge in Weeraketiya DS division of Sri Lanka, Tropical Agricultural Research, 2010, 21 (4): 330-339. 
[25] Elankumaran, C. 2003, Malnutrition in pre-school children of Jaffna Society-A post-exodus statistics perspective proceeding at the 9 th International conference on Sri Lanka Studies, 28 th - 30 th November 2003, Matara, Sri Lanka.

[26] Rajapaksha, L. and Fernando, D. N. 1987, Sex difference as a risk factor in child malnutrition, Ceylon Journal of Child Health, pp 17-25.

[27] Walia BNS, Gambhir SK. The relationship between child malnutrition and maternal knowledge and beliefs regarding nutrition. Ind Pediatr 1975; 12: 563-68.

[28] Srikantia SG, Sasty CY. Effect of maternal attributes on malnutrition in children. Proceedings of the First Asian Congress on Nutrition. J. Hyderabad, India. 1972: 584.
[29] Islam MA, Rahman MM, Mahalanabis D.1944. Maternal and socioeconomic factors and the risk of severe malnutrition in a child: a case-control study, Eur J Clin Nutr. ; 48 (6): 416-24.

[30] Charmarbagwala, R., Ranger, M., Waddington H., White, H. 2013. The determinants of Child health and nutrition: A Meta-Analysis received at Child health-nutrition.pdf on 19/9/2014.

[31] Cohen, n. 1981, Smoking, health and survival prospect in Bangladesh, Lancet; 16.

[32] B. A. Abuya, J. M. Ciera and Kimani-Murage (2012). Effect of Mother's Education on child's Nutritional status in the slums of Nairobi. BMC Pediatr. Vol 80; 8229: 1222-1233. 